\title{
ARTIGO
}

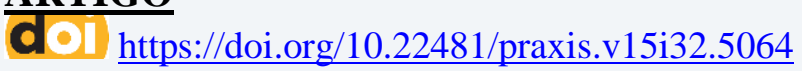

\section{PROCESSO FORMATIVO ESCOLAR EM CONEXÃO COM A REALIDADE DO \\ CAMPO: UMA ESCOLA POTENCIALIZANDO ESSA FUNÇÃO EDUCATIVA}

\author{
EDUCATIONAL FORMATION PROCESS IN CONNECTION WITH THE FIELD \\ REALITY: A SCHOOL STRENGTHENING THIS EDUCATIONAL ROLE
}

\begin{abstract}
PROCESO FORMATIVO ESCOLAR EN CONEXIÓN CON LA REALIDAD DEL CAMPO: UNA ESCUELA POTENCIALIZANDO ESTA FUNCIÓN EDUCATIVA
\end{abstract}

\author{
Dulcinéa Campos \\ Universidade Federal do Espírito Santo - Brasil
}

José Américo Cararo

Universidade Federal do Espírito Santo - Brasil

\begin{abstract}
Resumo: Apresenta-se o processo formativo de uma ação de extensão de formação de professores, realizado em uma escola pública de ensino fundamental e médio, com o objetivo de aprofundar reflexões teórico-metodológicas em torno dos desafios dos processos formativos escolares, em conexão com as condições objetivas dos sujeitos que vivem no e do campo. Referendado pela perspectiva histórico-dialética, adota a epistemologia da práxis , com a perspectiva de gerar, durante o desenvolvimento dessa ação, um processo epistêmico que reverbera na produção de conhecimentos em que se assegura a dialética entre os saberes escolares e suas relações com meio social. Por se tratar de uma escola de contexto rural, realizou-se um diagnóstico do entorno da escola, por meio de um inventário da realidade que adotou o agroecossistema como categoria de análise. Dentre as fontes vivas de conhecimentos levantadas, a escola elegeu como questão inicial e disparadora desse processo, o uso indiscriminado de agrotóxico na produção de alimentos na região. Emergiram, desse mesmo inventário, conhecimentos produzidos no campo, envolvendo modos de produção agrícola saudável. Esse olhar para além da escola, contribuiu para uma organização do trabalho docente focado no planejamento de processos, possibilitando uma relação entre teoria e prática.
\end{abstract}

Palavras chave: Educação do campo; Epistemologia da práxis; Organização coletiva do trabalho pedagógico.

Abstract: A clipping from the formation process of Teachers' training extension action that took place at public elementary and high school is presented with the purpose to deepen theoreticalmethodological reflections concerning the educational formation process, in connection with the objective conditions of the ones living in the countryside (field).Since the work is referenced by the historical-dialectical perspective, it uses the praxis (practice) epistemology, aiming at creating, throughout this action development, an epistemic process that reverberates in the production of knowledge in which the dialectics between school knowledge and their relations with the social 
environment is assured. On the account of being a school within the rural context, a diagnosis in the school surroundings was carried out, through a reality inventory that used the agroecosystem as an analysis category. Among the living sources of knowledge raised, the school chose as the initial and triggering issue of this process, the indiscriminate use of pesticides in food production in the region. From this same inventory emerged, knowledge produced in the field, involving healthy agricultural production methods. This look beyond the school, contributed to an organization of the teaching work, focused on the planning of processes, allowing a relation between theory and practice.

Keywords: Field (country) education, Praxis epistemology; Collective organization of the pedagogical (teaching) work.

Resumen: Se presenta el proceso formativo de una acción de extensión de formación de profesores, realizado en una escuela pública de Enseñanza Fundamental y Media, con el objetivo de profundizar reflexiones teórico-metodológicas en torno a los desafíos de los procesos formativos de la escuela, en conexión con las condiciones objetivas de los sujetos que viven en el campo. En el marco de la perspectiva histórico-dialéctica, adopta la metodología de las praxis, con la perspectiva de generar, durante el desarrollo de esa acción, un proceso epistémico que reverbera en la producción de conocimientos en que se asegura la dialéctica entre los saberes de las escuelas y sus relaciones con medio social. Por tratarse de una escuela de contexto rural, se realizó un diagnóstico del entorno de la escuela, por medio de un inventario de la realidad que adoptó el agroecosistema como categoría de análisis. Entre las fuentes vivas de conocimientos planteados, la escuela eligió como cuestión inicial y desencadenante de ese proceso, el uso indiscriminado de agrotóxico en la producción de alimentos en la región. De ese mismo inventario surgieron, surgidos, conocimientos producidos en el campo, envolviendo modos de producción agrícola sana. Esta mirada más allá de la escuela, contribuyó a una organización del trabajo docente enfocado en la planificación de procesos, posibilitando una relación entre teoría y práctica.

Palabras clave: Educación del campo; Epistemología de la praxis; Organización colectiva del trabajo pedagógico.

\section{Introdução}

Este artigo traz narrativas reflexivas sobre os desafios processuais de uma ação pedagógica, desenvolvida por professores da área de linguagens de uma escola pública de ensino fundamental e médio, situada no meio rural, em parceria com a universidade. Referendado pela historicidade e dialética entre os processos formativos escolares e as práticas sociais dos sujeitos do campo, adota a metodologia da práxis como caminho mobilizador de um processo epistêmico que reverbera na produção de conhecimentos vinculados a um projeto de formação humana emancipatória de educação e de escola. Tratase de uma visão relacional de conhecimento que o entende como parte de uma totalidade formativa, cujos ingredientes da práxis é a compreensão e transformação da realidade social (CALDART, 2017). 
Ancorado nessa concepção de conhecimento, este estudo busca compreender os desafios processuais de uma ação pedagógica desenvolvida desde as situações concretas dos sujeitos do campo e identificar as propostas pedagógicas mediadoras que emergem no desenvolvimento de ações formativas escolares, articuladas com os fenômenos da realidade do entorno da escola. Essa perspectiva provoca a escola a desviar o foco sobre si mesma como centro para pensar na direção de um projeto educativo que extrai do movimento real da história em processo o material que vai compondo o projeto formativo dos sujeitos, sempre vinculado aos seres humanos, à sua ação material e às suas vidas (CALDART, 2018).

O campo é um espaço social de produção de vida, compreendido como um território onde os sujeitos produzem as suas formas próprias de existências de modo articulado entre si e com a sociedade mais ampla, cabendo à escola, nessa direção, pensar na educação desses sujeitos desde esse território. Conforme assinala Caldart (2018, p. 14), trata-se de um lugar específico, sendo fundamental que a escola observe e pesquise o seu entorno "[...] para compreender o fenômeno da vida, em suas diferentes dimensões e relações". De acordo com essa autora, no campo há diversos sistemas produtivos, há recursos naturais, há pessoas, há trabalho, há cultura, há lutas com profundas contradições, cujas soluções exigem novas maneiras de conceber o campo e a sua relação com a educação. Nesse espaço/tempo denominado campo, há um agroecossistema, “[...] constituído por diferentes sistemas produtivos, por recursos naturais e pelas pessoas em suas relações de trabalho e de convivência, pelas instalações de trabalho e área de moradia” (ALTIERI, (2012, p. 183). Nesse agroecossistema há diversidades de processos formativos que possibilitam a ampliação da visão da escola, dando-lhe condições de se tornar parte dele, por meio da ligação que ela estabelece com a vida (trabalho, luta, cultura, organização social, história). Essa relação, obviamente, exige uma formulação pedagógica que possibilita a apropriação de conhecimentos necessários à construção de novas relações sociais e de relações equilibradas entre o ser humano e a natureza (CALDART, 2017). A escola, nessa direção, vai se constituindo num espaço de formação humana multidimensional e um centro cultural de referência para a comunidade.

A relação entre vida e escola não é um processo espontâneo. Ele exige uma organização metodológica, capaz de materializar essa relação de forma que se conheçam as “[...] condições e as potencialidades que existem no entorno da escola e nos processos que ela já desenvolve" (CALDART, 2017, p. 14). Uma das ferramentas apontadas pela autora, para materializar essa ligação, é o inventário da realidade, por meio do qual a escola, além de conhecer o lugar em que está inserida, as suas relações sociais e ecológicas, analisa 
dialeticamente como essas questões estão relacionadas com a realidade mais ampla. Todo esse movimento inclui uma determinada concepção tanto de educação quanto de escola.

No interior dessa materialidade, este artigo apresenta o movimento real formativo gerado na escola do campo, constituído no contexto da práxis pedagógica, partindo do princípio de que, mesmo em situações escolares adversas ao exercício da práxis, é possível pensar em uma formação escolar em conexão com a vida. Desse modo, este trabalho, desenvolvido em pareceria com a universidade, nasceu de um diálogo com os profissionais da escola, em um encontro realizado para discussão da proposta do desenvolvimento de estágio curricular obrigatório do Curso de Licenciatura em Educação do Campo, visto que essa escola acolheria, à época, uma das estudantes do referido curso para o cumprimento de seu estágio docente.

Salientou-se, na ocasião, que os estágios dessa licenciatura têm, como proposta, a prática docente, por área de conhecimentos, vinculada à realidade concreta dos sujeitos educandos. Ficou esclarecido que essa licenciatura tem por princípio formativo do professor, a "[...] construção do conhecimento necessário à sua formação de educador, não apenas nos espaços formativos escolares, mas também nos tempos de produção da vida nas comunidades onde se encontram as Escolas do Campo" (MOLINA; SÁ, 2012, p. 470). A escola demonstrou interesse em aprofundar esse debate e para isso sugeriu uma parceria com a universidade. Assim, deu-se início à discussão e elaboração do projeto de extensão, com posterior execução, conforme se apresenta adiante.

Tendo em vista essas considerações projetivas como primeira parte deste artigo, apresenta-se a segunda parte na qual se discute a escola do campo e o seu entorno como espaço/tempo de formação humana, o que indicou a necessidade de um movimento que transcendesse os limites disciplinares e se ganhasse novos contornos, mediante os diversas fontes vivas de conhecimentos produzidos nas relações sociais dos sujeitos do campo. A terceira parte traz reflexões sobre os movimentos globais de degradação da vida no planeta e discute princípios fundamentais da ecologia da vida no processo formativo dos sujeitos, como forma de geração e preservação da vida. A quarta parte apresenta o movimento real de formação desenvolvido na escola, destacando os limites e possibilidades de uma proposta formativa escolar que assume a metodologia da práxis como princípio educativo. A terceira parte tece-se as considerações finais.

\section{A escola do campo como espaço/tempo de formação humana e de construção de novas relações sociais}


A escola, que se situa no meio rural, é identificada pelo Decreto $n^{\circ} 7352 / 2010$, de escola do campo. À luz dessa legislação, escola do campo é tanto aquela situada em área rural como também as situadas em áreas urbanas, desde que em sua maioria atendam à população rural. Essa denominação coloca sobre essas escolas uma responsabilidade social de desenvolver seus processos formativos desde o campo, que tem em suas perspectivas, uma concepção de educação e de práticas para além de seus muros ou cercas, de modo que a ciência ganhe significado no contexto social desses sujeitos. Nesse contexto discursivo, a escola do campo, como espaço de formação humana, é provocada a substituir o isolamento convencional das disciplinas e as formas fragmentadas de seu ensino por uma educação que ofereça respostas necessárias às exigências da realidade, contribuindo com a compreensão de suas contradições e, ao mesmo tempo, oferecendo elementos fundamentais para a construção de novas relações sociais.

Como parte do processo formativo, foi realizado na escola um encontro em que se discutiu o resultado de um inventário sobre o agroecossistema do entorno da escola, como atividade de estágio de uma licencianda do Curso de Licenciatura em Educação do Campo. Esse levantamento identificou várias fontes de conhecimentos no entorno da escola, especialmente sobre formas de produção de alimentos, o que possibilitou uma primeira discussão sobre possibilidades organizativas do trabalho pedagógico. Nesse sentido, concorda-se com Caldart sobre a defesa da necessidade de haver:

[...] em cada momento histórico, para todos os trabalhadores, do campo e da cidade, uma matriz formativa alargada, multilateral, que amplie horizontes e que não seja restrita à preparação para o trabalho, mesmo que complexo. Uma matriz que inclua a educação pelas artes, pela literatura, o acesso às ciências que permitam entender o ser humano, a natureza, a sociedade, que ajudem no desenvolvimento mais pleno das pessoas, porque isso é direito humano e é necessário à construção criativa de novas relações sociais. (CALDART, 2016, p. 101).

A identificação das diversas fontes vivas de conhecimentos levantados nesse inventário remeteu à construção de uma matriz formativa que contribuísse com a “[...] instauração de relações sociais baseadas na igualdade e no respeito à diversidade, entre os seres humanos e na natureza' (CALDART, 2016, p. 108). Contudo, essa possibilidade mexeu com uma concepção de educação, de escola com toda a sua estrutura organizativa e epistemológica e, com isso, o grupo de professores foi tomado por várias dúvidas, o que gerava muitas inseguranças sobre o como fazer, pois a escola tinha, como característica 
comum, uma matriz formativa com a predominância dos conteúdos escolares sem vínculo com a realidade dos sujeitos. O desafio que se revelou nesse diálogo colocou, diante daquele grupo de educadores, a urgência da compreensão de uma concepção que oferecesse as bases necessárias para a construção de uma matriz curricular multidimensional e omnilateral. É importante ressaltar que essa necessidade não surgiu num vácuo, mas foi demandada por uma situação de base real. De um lado, a vida pulsando com todas as suas formas de diversidade e, de outro, a escola, com o seu currículo fechado e apartado desse mundo, ou seja, de um lado, as demandas da realidade concreta e dos sujeitos concretos e, de outro, a organização escolar e seu mecanismo de controle curricular para atender às necessidades avaliativas de larga escala. O grupo estava diante de uma questão cuja resposta precisava ser encontrada coletivamente.

Em vista desse impasse, várias questões foram colocadas: como fazer uma organização pedagógica articulada com temas da vida, uma vez que o sistema de ensino orienta e exige um movimento inverso? Como tirar um tempo, em meio a tantas demandas escolares, para pensar uma prática pedagógica coletiva e inter/transdisciplinar com os estudantes e a comunidade? Ao mesmo tempo que esse grupo ia fazendo as indagações, ia também percebendo que as resposta não viriam externas a eles, mas deles mesmos. Esse momento reflexivo constituiu-se em um importante encontro de formação com vista à emancipação desses professores. Essas indagações já eram em si evidências de mudanças entre os educadores, pois, desde então, eles sentiram necessidade de conjugar esforços coletivos, o que, obviamente, contrariava as orientações hegemônicas de currículo e de educação.

Uma das soluções encontradas para a viabilização de momentos coletivos de discussões, reflexões e planejamentos foi o espaço existente no próprio calendário escolar que tinha um dia semanal reservado para os professores da mesma área realizarem os seus planejamentos. Salientaram que só era possível usar parte desse tempo, visto que a maior parte do tempo deveria ser destinada ao preenchimento de pautas eletrônicas, correção de atividades de provas e preparação da recuperação para os alunos com notas abaixo da média. Incluía, também, nesse dia de planejamento, a organização da sequências de conteúdos, provenientes de programas advindos das parcerias público/privado. Nesse sentido, considerando o acúmulo de tarefas dos docentes a serem realizadas nesse dia, ficou acordado que seria reservada uma parte desse tempo para a realização de momentos de estudos, reflexões e exercícios de elaboração e execução de uma organização coletiva do trabalho pedagógico em conexão com a realidade concreta dos alunos. 
Esse trabalho teve por princípio o planejamento de processos, que se diferencia teórica e epistemologicamente do planejamento de projetos que em geral, se desenvolvem sob um tempo determinado para começar e para acabar, ou atividades pontuais, tema transversal ou atividade solta. O processo reflexivo desencadeado na perspectiva da práxis foi o caminho trilhado com o firme propósito que o diálogo entre as disciplinas não se realiza pela via dos conteúdos escolares, mas pelo viés da vida. Em vista dessa opção, outras indagações surgiram: e o currículo oficial, como fica? Como responder à Secretaria de Educação que cobra o ensino dos conteúdos previstos em cada ano? E a preparação dos estudantes para as avaliações, como Prova Brasil etc.? Mais uma vez os educadores se viram diante de um impasse sobre o caminho a adotar coletivamente e de discutir a possibilidade de uma síntese conciliadora.

Encontrou-se, em Pistrak (2011), uma referência importante para pensar a educação e o ensino dos conteúdos, visto que ambos fazem parte da escola, mas é preciso incluir uma organização pedagógica que atinja, efetivamente, os objetivos de educação, que interliguem os diversos aspectos da vida. Conforme esse autor, a escola não prepara para a vida porque ela é, ou deveria ser a própria vida. Desse modo, a vida, o meio em que os sujeitos vivem, possui várias outras agências formativas, além da escola, que precisam ser conhecidas e levadas em conta no estabelecimento de objetivos de ensino. A possibilidade de conhecer o lugar em que vivem os sujeitos estudantes, suas relações sociais e ecológicas, vinculadas com as questões mais amplas da realidade, incorpora uma concepção de que a escola é parte de processos formativos que constituem a vida dos sujeitos em sociedade e que sua tarefa educativa se desenvolve em seu movimento histórico (CALDART, 2016).

O que muda, segundo esse autor, não são os conhecimentos científicos, mas os saberes pedagógicos necessários a uma docência que, por meio de suas práticas coletivas interdisciplinares, rompa com o invólucro que reveste as disciplinas, visto que ele é responsável por manter o isolamento entre elas. Além de seus isolamentos, esse invólucro é também responsável pela estrutura que aprisiona os conteúdos, cristalizados em livros e outros materiais didáticos (PISTRAK, 2011). Essa reflexão contribuiu para refletir sobre quais conteúdos seleciona para a compreensão de determinadas realidades.

Entender, portanto, a educação como formação humana, pressupõe romper com a concepção, ainda dominante, que vê a “[...] educação com função propedêutica, transmissiva, utilitarista, como uma 'preparação para a vida', que cada vez mais se reduz a uma preparação para competição no mercado de trabalho: é preciso competir para ser explorado pelo capital!” (CALDART, 2015, p. 28). Segundo essa autora, cabe à educação enfrentar o confronto de 
matriz formativa, o que implica mudanças significativas na organização do trabalho pedagógico em que educadores e educandos são envolvidos, visto que, enquanto o educador trabalhar isoladamente, por sua própria conta e sem o envolvimento dos estudantes, não haverá as mudanças significativas na escola.

\section{Cuidar de si, cuidar do outro e cuidar da natureza: a escola potencializando essa função social}

No atual cenário agrário brasileiro há segundo Alentejano, 2014, questões nucleares que precisam ser compreendidas localmente, como; a) a manutenção da concentração fundiária e as desigualdades dela derivadas; b) o processo frenético de internacionalização da agricultura brasileira, em relação ao controle da tecnologia, do processamento agroindustrial, da comercialização da produção agropecuária e da compra de terras; c) a crescente insegurança alimentar decorrente das transformações recentes na dinâmica produtiva da agropecuária; d) a perpetuação da violência, da exploração do trabalho e da devastação ambiental no campo brasileiro. Todas essas questões nucleares são partes de um modo de produção capitalista que produz fortes desigualdades no campo, cabendo, portanto, um estudo de como elas se manifesta e atua em cada contexto. São questões que trazem consequências graves para a vida em toda a sua diversidade de formas e manifestações, não somente a do ser humano.

A partir, sobretudo, do século XVI, consolidou-se mundialmente uma forma de pensar e fazer ciência ignorando, via de regra, que o ser humano não está acima ou além da complexa e multifacetada rede de interconexões entre os seres vivos que povoam o nosso planeta. A gravíssima crise socioambiental que atravessamos na atualidade, de dimensões planetárias, atesta as consequências da lógica antropocêntrica, afetando, também, a produção e socialização do conhecimento e o trabalho da instituição escolar. Crise que se manifesta no aquecimento global em curso, na destruição de variados biomas, extinguindo inúmeras espécies animais e vegetais, comprometendo a biodiversidade e penalizando também aqueles grupos sociais mais fragilizados e excluídos.

Com as grandes conquistas marítimas empreendidas pelos países europeus (França, Espanha, Portugal, Inglaterra, entre outros), no final do século XV e ao longo do século XVI, paradigmas orientadores das formas de viver e produzir foram se padronizando e impostos aos povos originais das terras conquistadas na América, na África, na Ásia e na Oceania. Muitas trocas culturais se efetivaram, sobretudo na alimentação e em certos hábitos e normas de 
proceder, mas as relações hierárquicas e verticais que se consolidaram depois intensificaram crescentemente a exploração predatória e utilitarista dos recursos naturais.

A conhecida carta atribuída ao índio estadunidense Seattle, cacique da tribo Duwamish, ilustra exemplarmente os desdobramentos desse processo que potencializou um verdadeiro biocídio no planeta Terra. Escrita em resposta à oferta de compra de suas terras pelo presidente dos EUA, no ano de 1855, faz-nos um alerta contundente em sua conclusão: "Tudo quanto agride a terra, agride os filhos da terra. Não foi o homem que teceu a trama da vida: ele é meramente um fio da mesma. Tudo que fizer à trama, a si próprio o fará" (FAGUNDES, 2004, p. 116).

Assim, desde a marca histórica da concentração fundiária, a insegurança alimentar promovida pelo fortalecimento do agronegócio, em detrimento da agricultura agroecológica, a violência no campo e a devastação ambiental, com destaque para o desmatamento, de um lado, e o uso cada vez mais intenso do agrotóxico, por outro, constituem o modelo hegemônico que atende ao modo de produção capitalista que segue em direção contrária à vida. Com relação ao agrotóxico, o seu uso, cada vez mais intenso, transformou o Brasil no maior consumidor mundial desde o ano de 2008 (ALENTEJANO, 2014). A compreensão prévia da complexidade das realidades do campo brasileiro provoca e impulsiona a escola na direção de um processo educativo emancipador e inclusivo que contribui na busca de uma nova síntese de projeto de agricultura construído nas bases dos movimentos sociais do campo e da cidade. De acordo com o geógrafo Porto-Gonçalves (2006, p. 71), “[...] seriam necessários cinco planetas para oferecermos a todos os habitantes da terra o atual estilo de vida vivido pelos ricos dos países ricos e pelos ricos dos países pobres. Portanto, é fundamental que a escola problematize a lógica de produção/consumo, bem como seus impactos nos processos de subjetivação estudantis e dê visibilidade ao que vem sendo construído com bases agroecológicas.

No que se refere à escola do campo, a prática e disseminação da agricultura agroecológica tem esse fundamento ético e educacional. Para isso, foram planejadas e realizadas dialogicamente, atividades grupais, interdisciplinares e diversificadas, como pesquisas na internet, produção de histórias em quadrinhos, desenhos, análises de audiovisuais, experiências desenvolvidas na comunidade, produções de textos envolvendo vários gêneros textuais, palestras com pessoas da comunidade sobre o modo de fazer agricultura saudável, relato de experiências dos próprios alunos que realizam essa prática nos lotes de terra pertencentes às suas famílias, mostras de vídeos, realização de visitas de estudos, pesquisas de campo, caminhada ecológica, entre outras. Nesse movimento, os 
educadores contemplam, também, um aspecto articulador relevante, qual seja, trabalhar os conteúdos selecionados nas diferentes escalas geográficas (local, regional, nacional e global), tentando compreender suas interconexões dinâmicas e complexas, favorecendo diálogos mais horizontais entre diferentes saberesfazeres produzidos e praticados, pois "[...] o que se requer é um saber presente, que dialogue com o lugar, que dialogue com os do lugar, e não que se imponha do alto, de fora, eis a questão" (PORTO-GONÇALVES, 2006, p. 87).

\section{A organização coletiva do trabalho pedagógico referenciado pela realidade dos estudantes: desafios e possibilidades}

A organização do trabalho docente depende da perspectiva epistemológica assumida pelos professores, conforme esclarece a tese de Neves (2-13). Essa autora assegura que, dada a solidez alcançada pelo projeto reformista de formação, o professor, em todos os níveis de ensino, vem se constituindo em importante intelectual orgânico da nova pedagogia da hegemonia que visa à adaptação das políticas de educação e de formação do docente aos padrões de sociabilidade privativista e aos requisitos técnicos, éticos, estéticos, políticos e culturais do capitalismo neoliberal, inscritos nas propostas dos organismos internacionais e do governo brasileiro, desde os anos iniciais da década de 1990. De acordo com essa autora, os professores estariam, desde então, sendo formados para atuar como intelectuais orgânicos da nova pedagogia da hegemonia, submetidos a uma formação que substituiu a epistemologia da práxis pelo foco na epistemologia da prática.

Assumindo nessa análise a epistemologia da práxis como base para pensar o trabalho educativo na escola, foram realizados diversos momentos formativos como: encontros de estudos e debates; encontros para análise dos dados da realidade expressos no inventário da realidade; encontros de organização do trabalho pedagógico coletivo; escolha do tema da realidade, das estratégias, dos objetivos a serem desenvolvidos na área de Linguagem; seleção de conteúdos demandados para a compreensão e intervenção da realidade em estudo; ações de integração com as comunidades; encontros presenciais para momentos avaliativos do processo; organização de eventos envolvendo a comunidade.

Com base na reflexão sobre os elementos levantados por meio do inventário da realidade do entorno da escola, chegou-se à seleção do primeiro tema/estudo - ouso de agrotóxico e suas consequências para a vida. Esse tema foi o primeiro a ser escolhido, tendo em vista que esse problema já vinha incomodando e preocupando a todos, porém a escola ainda não havia parado para desenvolver um processo formativo com as devidas mediações 
didático-pedagógicas em torno dessa problemática. Foi consenso entre todos que o uso indiscriminado de agrotóxico na agricultura estava sendo um problema na região que necessitava de intervenção com bastante urgência. Um professor enunciou o problema da seguinte maneira: pela manhã, quando venho para o trabalho é visível uma grande nuvem de agrotóxicos no ar. Isso gera ardência nos olhos e dificuldades na respiração.

Com essas considerações e ponderações sobre a relevância social da temática, foram discutidas formas de mediação em que se realizaria a conexão da necessária dialética entre os conteúdos e o tema da realidade. Para isso, foi necessária uma conjugação de esforços no planejamento coletivo para pensar uma organização pedagógica que reunissem os conteúdos necessários para a compreensão da complexidade do problema, tendo em vista que compreendê-lo implicaria uma variedade de informações e conhecimentos científicos que extrapolassem a organização educativa disciplinar.

Desse modo, não bastava a seleção de conteúdos para a compreensão do problema, apenas, pois, se de um lado há uma realidade com práticas de agricultura com agrotóxico, de outro, há também a possibilidade de produzir alimentos limpos, como caminho viável. O diálogo em torno das possibilidades de superação levou ao primeiro esforço coletivo de sistematização de currículo com a articulação entre saberes entre as duas temáticas: $\mathrm{O}$ uso de agrotóxico e suas consequências para a vida e a Agricultura agroecológica: alimentos saudáveis e sem veneno. Foi realizada uma organização, sabendo-se provisória, mas importante para que houvesse um início, conforme se apresenta no Quadro 1.

Quadro 1 - Organização coletiva do trabalho docente

\section{Tema 1: O uso de agrotóxico e suas consequências para a vida}

Primeiro momento: como diálogo inicial, foi realizado de um debate coletivo com a participação dos professores e dos alunos com a exibição do vídeo: O Brasil é considerado o maior consumidor de agrotóxico do mundo.

\begin{tabular}{|c|c|c|c|c|}
\hline Português & Educação Física & Arte & Ensino Religioso & Inglês \\
\hline $\begin{array}{l}\text { - Gênero textual: } \\
\text { Entrevista e } \\
\text { Relatório } \\
\text { - Organização de } \\
\text { um roteiro de } \\
\text { perguntas para } \\
\text { entrevista aos } \\
\text { agricultores da } \\
\text { região } \\
\text { - Relatório da } \\
\text { entrevista. }\end{array}$ & $\begin{array}{l}\text { - O estudo do } \\
\text { funcionamento do } \\
\text { sistema nervoso } \\
\text { central e a } \\
\text { preservação de } \\
\text { sua saúde. } \\
\text { - Estudo da } \\
\text { influência do uso } \\
\text { do agrotóxico } \\
\text { sobre o sistema } \\
\text { nervoso central } \\
\text { - Pesquisa sobre }\end{array}$ & $\begin{array}{l}\text { - Artes em } \\
\text { logotipos e } \\
\text { gráficos } \\
\text { - Leitura } \\
\text { imagética de } \\
\text { mídia que } \\
\text { divulga o } \\
\text { agrotóxico } \\
\text { - A criação } \\
\text { de logotipos } \\
\text { que } \\
\text { denunciam os }\end{array}$ & $\begin{array}{l}\text { - Os valores } \\
\text { humanos, éticos e } \\
\text { estéticos violados } \\
\text { com o uso de } \\
\text { agrotóxicos } \\
\\
\text { - Debate: "Eu só } \\
\text { coloco agrotóxico } \\
\text { nos alimentos que } \\
\text { vendo e nos do } \\
\text { consumo não } \\
\text { coloco". } \\
\text { - O significado das }\end{array}$ & $\begin{array}{l}\text { - As Multinacionais } \\
\text { que detêm o controle } \\
\text { na produção e venda } \\
\text { de agrotóxicos, } \\
\text { agroquímicos e } \\
\text { transgênicos }\end{array}$ \\
\hline
\end{tabular}




\begin{tabular}{|c|c|c|c|c|}
\hline $\begin{array}{l}\text {-Processos de } \\
\text { escrita e } \\
\text { reescrita do } \\
\text { relatório. } \\
\text { - Seminário para } \\
\text { leituras dos } \\
\text { relatórios e } \\
\text { realização de } \\
\text { síntese. } \\
\text { - Apresentação } \\
\text { nos eventos } \\
\text { escolares e nos } \\
\text { murais da } \\
\text { escola. }\end{array}$ & $\begin{array}{l}\text { as principais } \\
\text { doenças } \\
\text { provocadas pelo } \\
\text { uso e consumo do } \\
\text { agrotóxico } \\
\text { - Debate e } \\
\text { reflexões sobre o } \\
\text { vídeo parte II: O } \\
\text { veneno está na } \\
\text { mesa }\end{array}$ & $\begin{array}{l}\text { malefícios do } \\
\text { agrotóxico }\end{array}$ & $\begin{array}{l}\text { místicas realizadas } \\
\text { pelos camponeses, } \\
\text { adotando o } \\
\text { agrotóxico como } \\
\text { categoria reflexiva. } \\
\text { - Leitura, releitura, } \\
\text { análise e } \\
\text { dramatização do } \\
\text { poema de Cora } \\
\text { Coralina: Terra }\end{array}$ & $\begin{array}{l}\text { - Formação de frases } \\
\text { ou textos em inglês } \\
\text { realçando os } \\
\text { malefícios do } \\
\text { agrotóxico }\end{array}$ \\
\hline \multicolumn{5}{|c|}{$\begin{array}{l}\text { Momentos coletivo entre professores, alunos e membros da comunidade: } \\
1 \text { - Exibição do vídeo: Agricultura orgânica: momento ambiental } \\
2 \text { - Palestra com pessoas da comunidade, Movimento dos Pequenos Agricultores, Movimento dos } \\
\text { Trabalhadores Sem Terra e Assentados da Reforma Agrária que praticam a agricultura agroecológica. }\end{array}$} \\
\hline Português & Educação Física & Arte & Ensino Religioso & Inglês \\
\hline $\begin{array}{l}\text { - Os } \\
\text { conhecimentos } \\
\text { linguísticos } \\
\text { envolvendo } \\
\text { leituras e } \\
\text { produção de } \\
\text { textos } \\
\text { - Produção de } \\
\text { textos } \\
\text { considerando as } \\
\text { questões } \\
\text { textuais, como } \\
\text { coerência e } \\
\text { coesão } \\
\text { - Coletânea e } \\
\text { mostra dos textos } \\
\text { produzidos pelos } \\
\text { alunos }\end{array}$ & $\begin{array}{l}\text { - Expressão } \\
\text { corporal com } \\
\text { dança de roda e } \\
\text { cirandas } \\
\text { camponesas. } \\
\text { - A relação do } \\
\text { corpo com o } \\
\text { alimento na } \\
\text { realização de } \\
\text { exercícios e o } \\
\text { desenvolvimento } \\
\text { corporal } \\
\text { - Práticas } \\
\text { esportivas e sua } \\
\text { relação com um } \\
\text { planejamento } \\
\text { alimentar }\end{array}$ & $\begin{array}{l}\text { - Músicas } \\
\text { populares e } \\
\text { da educação } \\
\text { do Campo e } \\
\text { dos } \\
\text { movimentos } \\
\text { camponeses } \\
\text { - Mística } \\
\text { dos } \\
\text { movimentos } \\
\text { sociais e sua } \\
\text { forma de } \\
\text { expressar a } \\
\text { sua relação } \\
\text { com a } \\
\text { natureza. } \\
\text { - Aprendendo } \\
\text { a pintar e } \\
\text { desenhar com } \\
\text { a natureza } \\
\text { - Elaboração } \\
\text { de tirinhas }\end{array}$ & $\begin{array}{l}\text { - Ética: A relação: } \\
\text { vida, produção de } \\
\text { alimentos, ar, solo } \\
\text { e ar. } \\
\text { - O sentido } \\
\text { humano expresso } \\
\text { nas lutas por } \\
\text { justiça social no } \\
\text { campo. } \\
\text { - Os Movimentos } \\
\text { Sociais do Campo } \\
\text { e a função social da } \\
\text { terra. } \\
\text { - A reforma } \\
\text { Agrária e sua } \\
\text { importância para a } \\
\text { justiça social e } \\
\text { distribuição de } \\
\text { renda. }\end{array}$ & $\begin{array}{l}\text { - Leitura, escrita e } \\
\text { estudo da pronúncia } \\
\text { de palavras e textos } \\
\text { em inglês sobre a } \\
\text { agricultura } \\
\text { agroecológica } \\
\text { - Leitura e escrita, } \\
\text { em inglês, dos nomes } \\
\text { das principais } \\
\text { culturas da região. } \\
\text { - A relação dos } \\
\text { países de língua } \\
\text { inglesa com o uso do } \\
\text { agrotóxico nos } \\
\text { alimentos. }\end{array}$ \\
\hline
\end{tabular}

Fonte: Elaborado pelos autores (2017)

Esse momento, com a intenção de sistematizar a ação pedagógica em torno de um tema real, constituiu-se em um exercício árduo e impaciente de pensar o fazer juntos. Desencadeou um movimento tenso entre o desejado e os limites impostos pela instituição. 
Como era de se esperar, essa configuração inicial, conforme concebido, sofreu alterações durante o processo, o que foi muito bom, porque levou os professores a criar novas possibilidades sobre as condições de trabalho existentes. Os obstáculos que iam sendo impostos pela estrutura organizativa escolar, fortaleceu o processo e, o que parecia obstáculo, foi se transformando em possibilidades. O tensionamento ocorria entre a cobrança pela Secretaria de Educação para cumprir o seu currículo e programas e o que estava sendo discutido como uma necessidade real da comunidade.

Como dito, dentro das condições reais, a escola foi construindo um caminho próprio, dentro de suas possibilidades e compreensão. Como atividade inicial desenvolvida com os alunos em torno do primeiro tema, foi exibido o vídeo $O$ veneno está na mesa, de autoria do cineasta Silvio Tendler que, por meio dos relatos de especialistas e agricultores, coloca em xeque o atual modelo de produção de alimentos. O Brasil é identificado como o maior consumidor de agrotóxicos, de sorte que cada brasileiro consome, em média, 5,2 litros por ano. O filme conclui que, se as pessoas quiserem continuar vivendo e salvar o planeta, precisam buscar outro modelo de agricultura orgânica. Temos que abandonar os transgênicos e os defensivos agrícolas, que nada mais são do que agrotóxicos.

O segundo tema - a agricultura agroecológica : alimentos saudáveis e sem veneno, que assim como o primeiro tema, foi realizado momentos com exibição e debate de vídeos esclarecedores. De acordo com os professores, foi muito bom o debate com os estudantes, porque eles tinham muito a dizer e contribuir, visto que essa questão fazia parte de seus cotidianos. Uma professora destacou que As aulas fluíam e eram bastante movimentadas porque os alunos participavam com as suas experiências. Eles vivem essas práticas agroecológica com as suas famílias nos assentamentos onde moram. Esses alunos falavam das lutas existentes no campo para combater veementemente o modelo de produção que está exaurindo a terra de suas condições naturais de produção da água, do ar e de alimentos, denominado de agronegócio.

Nessa direção, atividades variadas foram desenvolvidas no contexto das disciplinas, como visitas às localidades agrícolas do campo; diálogos com os camponeses; produções de textos pautados em escritas críticas e propositivas; desenhos e pinturas da natureza morta e viva; pintura com o colorido das frutas, legume e hortaliças; socialização das atividades no mural da escola; pesquisa na internet, que repercutiu no aprendizado de muitos conhecimentos relacionados com os temas; práticas esportivas e modos saudáveis de vida; influência do agrotóxico sobre o sistema nervoso central e a prática de exercícios físicos; diversas formas de contaminação ambiental; organização de uma caminhada ecológica a favor da vida; 
seminário para apresentação das pesquisas realizadas na internet; palestra com pessoas da comunidade que utilizam a agroecologia na produção de alimento; organização de uma feira científica com a participação de outras áreas de conhecimento; sarau com apresentação de músicas, poemas e teatro elaborados pelos próprios estudantes e uma participação especial na câmara de vereadores em uma audiência pública sobre o uso indiscriminado do agrotóxico.

A visibilidade das produções dos alunos testemunharam a diversidade de aprendizagens que se destacaram pelas denúncias de uma realidade contraditória e desigual e também pelo anúncio de muitas possibilidades de superação, mostrando que outra forma de produzir alimentos e de relacionar com a natureza é possível, necessária e urgente, conforme salienta o poema construído por uma aluna do $7^{\circ}$ ano:

\section{O agrotóxico no dia a dia}

Acordando bem cedinho,

$\mathrm{O}$ cheiro forte vai surgindo

Os animais no campo

Não têm outro canto.

As pessoas enlouquecendo

Pois os alimentos estão se perdendo.

De canto a canto não tem lugar

Pois não podem mais se alimentar

No dia de hoje não podemos confiar

Nos supermercados as frutas não podemos comprar

Com este gosto de veneno

As pessoas estão adoecendo.

O que podemos fazer?

Sobre o que vai acontecer.

Fazendo uma campanha

Isso poderá resolver.

No poema acima, a autora anuncia o conteúdo temático, iniciado pelo título $O$ agrotóxico no dia a dia. Ele compõe o prenúncio de um conflito narrativo, em que a autora, de forma atônita e emancipada, se coloca frente a frente com uma realidade contraditória, soltando uma pergunta no horizonte como se fosse um grito de socorro, ou seja, uma forma de buscar uma adesão ampla e coletiva para o problema em pauta:

O que podemos fazer?

Sobre o que vai acontecer.

Fazendo uma campanha

Isso poderá resolver. 
A escrita segue as normas composicionais do gênero poema e verifica-se nesta análise, a sua configuração textual, a sua estrutura, o seu léxico, a sua gramática e a semântica em todo o texto, composto por narrativas que expressam relações com a realidade concreta do tema em estudo. O poema traz uma discursividade que evidencia um ensinoaprendizagem dos conhecimentos do sistema da língua mediados pelo mundo.

\section{Considerações finais}

Considerando que este artigo é bem menor que o movimento real das práticas que o compõe, mesmo assim, entendemos que essa sistematização e divulgação das reflexões sobre este movimento significa muito para o avanço da história no âmbito da práxis educativa. Revela, entre outras coisas, o desafio da realização de um trabalho pedagógico centrado na compreensão do fenômeno da vida em suas múltiplas determinações, dentro de uma instituição escolar que possui todos os dispositivos colocados a serviço de um currículo predeterminado pelo sistema de ensino, que tem como centro os conteúdos desvinculados de sua base social.

No contrafluxo do movimento escolar que individualiza os sujeitos e fragmenta os conteúdos, a realidade é colocada como centro, em torno da qual se articulam os conteúdos escolares. Isso exige a organização de um trabalho pedagógico coletivo, de forma que professores e alunos “[...] desenvolvam a capacidade de articular a leitura de suas realidades, valendo-se do conhecimento científico, aprofundando desde as releituras e análises que vão se tornando complexas à medida que os educandos vão avançando em sua escolarização [...]" (MOLINA, 2015, p. 141), tendo como perspectiva as intervenções em suas comunidades.

Foram muitas as intercorrências que atravessaram o percurso deste trabalho, impossibilitando que o pensado fosse materializado no contexto da ação e, por isso, muitos recuos, retomadas e adequações foram necessários. A escola é sobrecarregada com programas e projetos prontos, advindos da Secretaria de Educação a que pertence, e que precisam ser executados. Há, nessa direção, formas de controle rígido, o que inclui os registros em tempo real nos diários de classe eletrônicos o que absorve uma grande parcela do tempo dos professores, deixando pouco tempo para as suas elaborações e organizações docentes. Esse pouco tempo para planejamento e formulação da prática docente que reúne teoria e prática no mesmo movimento, se deve ao fato de os professores são pensados pelos programas que adentram a escola sem que haja para isso, uma mínima discussão. Todavia, durante este percurso formativo na escola, observou-se um movimento de vida acontecendo, de 
contradições em explosão, de um exercício de pensar juntos, de contraposição à lógica dos programas formativos fundamentados no ativismo pedagógico em que as formas de capacitação dos professores são colocados no lugar de executores de programas.

Como dito, a ação formativa na referida escola não partiu de um modelo préestabelecido, mas se enveredou pelas possibilidades de professores e alunos serem os formuladores de suas ações. Isso, obviamente, gerou inicialmente, um estranhamento, mas, na medida em que o trabalho foi se constituindo, foi também, reafirmando a convicção de que a vida aponta para a escola formas próprias de organização curricular, de acordo com o seu movimento real.

Conclui-se que este processo, cheio de curvas e atropelos, assim como é o dia-a-dia da vida, foi muito rico do ponto de vista social, formativo e criativo porque ele não foi artificialmente criado, contudo, houve uma constatação que trabalhar pedagogicamente a realidade implica organização de processos formativos específicos nessa direção.

\section{REFERÊNCIAS}

ALENTEJANO, Paulo. Questão agrária e agroecologia no Brasil do século XXI. In: MOLINA, Mônica Castagna et al. Práticas contra-hegemônicas na formação dos profissionais das Ciências Agrárias: reflexões sobre a agroecologia e Educação do Campo nos cursos do Pronera.

ALTIERI, Miguel. Agroecologia: bases científicas para uma agricultura sustentável. 3. ed. Ver. E ampl. São Paulo/Rio de Janeiro: Expressão Popular/AS-PTA, 2012.

CALDART, Rosely Salete. Pedagogia do movimento e complexos de estudo. In:

CALDART, Roseli Salete; FREITAS, Luiz Carlos de; SAPELLI, Marlene Lucia Siebert.

Caminhos para a transformação da escola. 3. São Paulo, Editora: Expressão Popular, 2015.

CALDART, Rosely Salete (Org). Caminhos para a transformação da escola 4: trabalho, agroecologia e estudos nas escolas do campo.Editora: Expressão Popular, São Paulo, 2017.

CALDART, Rosely Salete. Educação do campo 20 anos: a construção de um projeto políticoformativo. Mesa compartilhada com Givânia Maria da Silva (Conaq), Gersem Luciano (Baniwa - Ufam), Maria do Socorro Silva (UFCG) e Maria Isabel Antunes (UFMG). Fórum Nacional de Educação do Campo (Fonec): Encontro Nacional - 20 anos Educação do Campo e Pronera. Brasília/DF, 12 a 15 de junho 2018.

CALDART, Rosely S. Pensando a educação dos camponeses. In: Carmen Rejane Flores Wizniewsky, Leonice Aparecida de Fátima Alves Mourad (org). Educação, memória e resistência popular na formação social da América Latina, Porto Alegre : Evangraf, 2016.

FAGUNDES, Márcia. Quero ser do bem. Belo Horizonte: Autêntica, 2004. 
MOLINA, Mônica Castagna; HAJE, Salomão Mufarrej. Política de formação de educadores do campo no contex to da expansão da educação superior.Revista Educação em Questão, Natal, v. 51, n. 37, p. 121-146, jan./abr. 2015.

PISTRAK, M.M. Fundamentos da escola do trabalho. $3^{\text {a }}$ ed. São Paulo: Expressão Popular, 2011.

PORTO-GONÇALVES, Carlos Walter. A globalização da natureza e a natureza da globalização. Rio de Janeiro: Civilização Brasileira, 2006.

\section{$\underline{\text { SOBRE OS AUTORES }}$}

\section{Dulcinéa Campos}

Doutora em Educação pela Universidade Federal do Espírito Santo (UFES). Professora da Graduação e Pós-Graduação em Educação da mesma universidade. Membro do Grupo de Estudos e Pesquisa Alfabetização, Leitura e Escrita e do Grupo de Estudo e Pesquisa em Educação do Campo do Espírito Santo. E-mail: dulcampos@gmail.com

\section{José Américo Cararo}

Doutor em Educação pela Universidade Federal do Espírito Santo (UFES). Professor de graduação no Centro de Educação/UFES. Membro do Laboratório de Ensino e Aprendizagem em Geografia da mesma universidade. Atua na linha de pesquisa formação de professores e em pesquisas articulando culturas, currículos, cotidianos e formação de educadores, com ênfase, sobretudo, em educação e mídia, ensino de Geografia e questões socioambientais. Email: ja.gaia@uol.com.br 